\title{
STUDY OF THE EFFECT OF URBAN WALLS ON SOCIAL INTERACTIONS
}

\author{
Narges Aboutaleb \\ M.S. in Architecture \\ Sahar Hasani Mianroudi \\ M.S. Student in Architecture \\ Farzad Saberi Movahed \\ M.S. Student in Architecture
}

\begin{abstract}
Facade of a building is effective in the shape of a city. These facades shape the view of city when they put together. The first panel introduces the city to travelers and tourists, that is why it is particularly important to introduce any area. Urban walls are the most important elements that affect the relationship between people and the improvement of living space, these walls bring their activities as well as public spaces and show culture of the people that unfortunately today abnormalities and visual disturbances have transformed the shape, form, color and materials of building facades, and view of cities. It's a descriptive study that it has been tried to define the urban facade and factors affecting the urban facade and walls. It also studies the concept of social interactions and impact of the city walls on interactions and relationships between people and expresses how visual disturbances can cause bodies to be heterogeneous and anonymous environment.
\end{abstract}

Keywords: city walls, facades, culture, social interaction, visual disturbances

\section{INTRODUCTION}

Exterior decoration of buildings play very important role to in showing that is the urban background of city. As designing decoration in the show tries to create the space related to the theme of the show, facades of building in city represent the events that occur in city. According to Harald Deilmann, four expectations of building façade are considered: protection, to communicate with people, to introduce and define the building as part of an urban space. Residents of a building facade should be protected from external threats and communicate between interior and exterior, with doors and windows. The membership process in city like any other membership requires to observe the rules that accepting them leads to harmony between other elements and lack of this commitement leads to confusion on the faces of the city and the obvious lack of accountability in this area (Pakzad, 2003).

\section{Urban landscape:}

The so-called face of the city in the context of urban design usually synonymous with "urban landscape" is used. The view of the city (or urban landscape) is: everything the city has seen in horizontal and vertical surfaces And the first step to understand urban environment without any mental reactions such as shooting in other words to mind. In the second step that cannot be separated from the first step, the image of city in mind accompanied with emotions and thoughts that this step is known as mental imagery. So we can say:

Face of the city: a city that has all the elements to be seen, the eye is able to watch it, and the human mind and memory are formed. Urban landscape: visual and structural integrity of buildings, streets and places that make up the urban environment (Yousefi, 2010). 


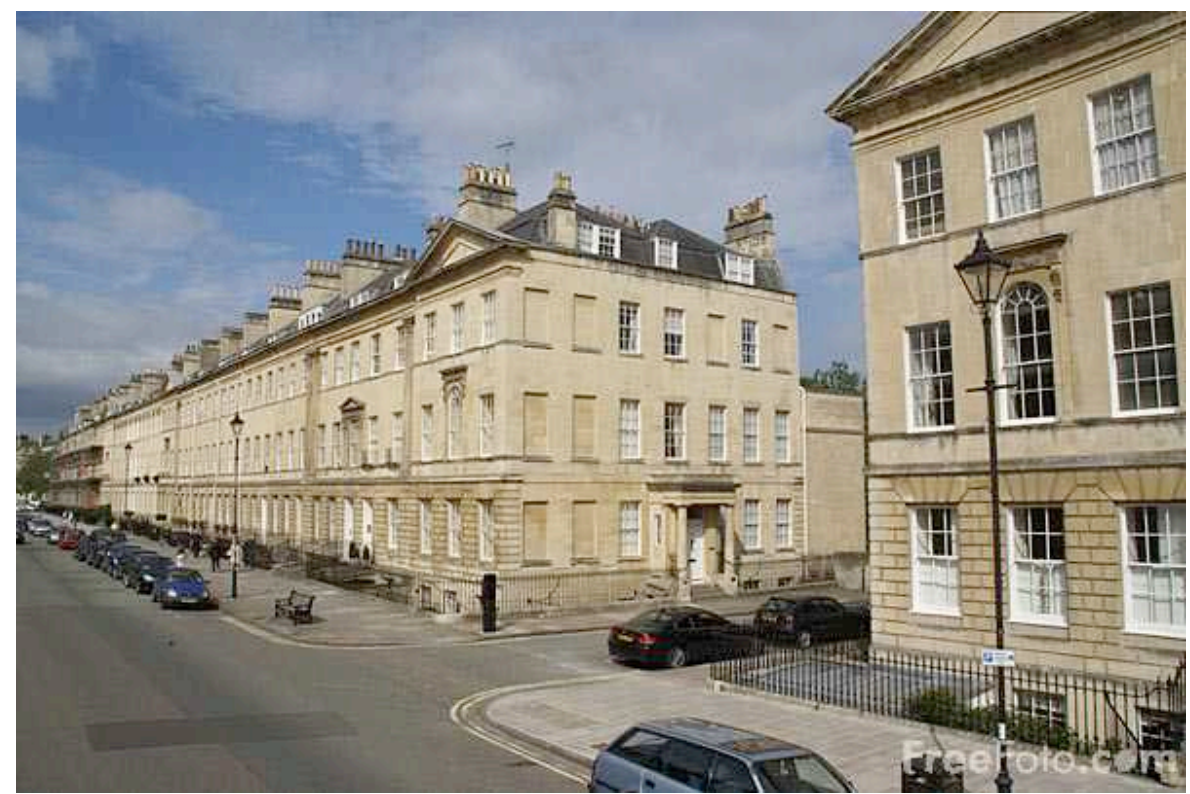

Figure 1: View of city

\section{VIEWS AND WALLS OF THE BUILDING}

Front appearance in dictionaries Dehkhoda mean everything that is in sight and eye, as seen from the outside, exterior view of the building and building, exterior and façade building, technology building and the facade of the mansion pavement. Posing on a flat surface is not flat, but it is the transition between interior and exterior rear-retirement and projection, terraces etc. will connect with the interior of the housing, for the frontage to preserve the privacy of their residents should be safer than more closed streets. The frontage must seek to create a harmony by a good fit windows, openings in, range hoods and roofs, vertical and horizontal structures, materials, colors, decorative elements, etc. (Banimahd, 2007).

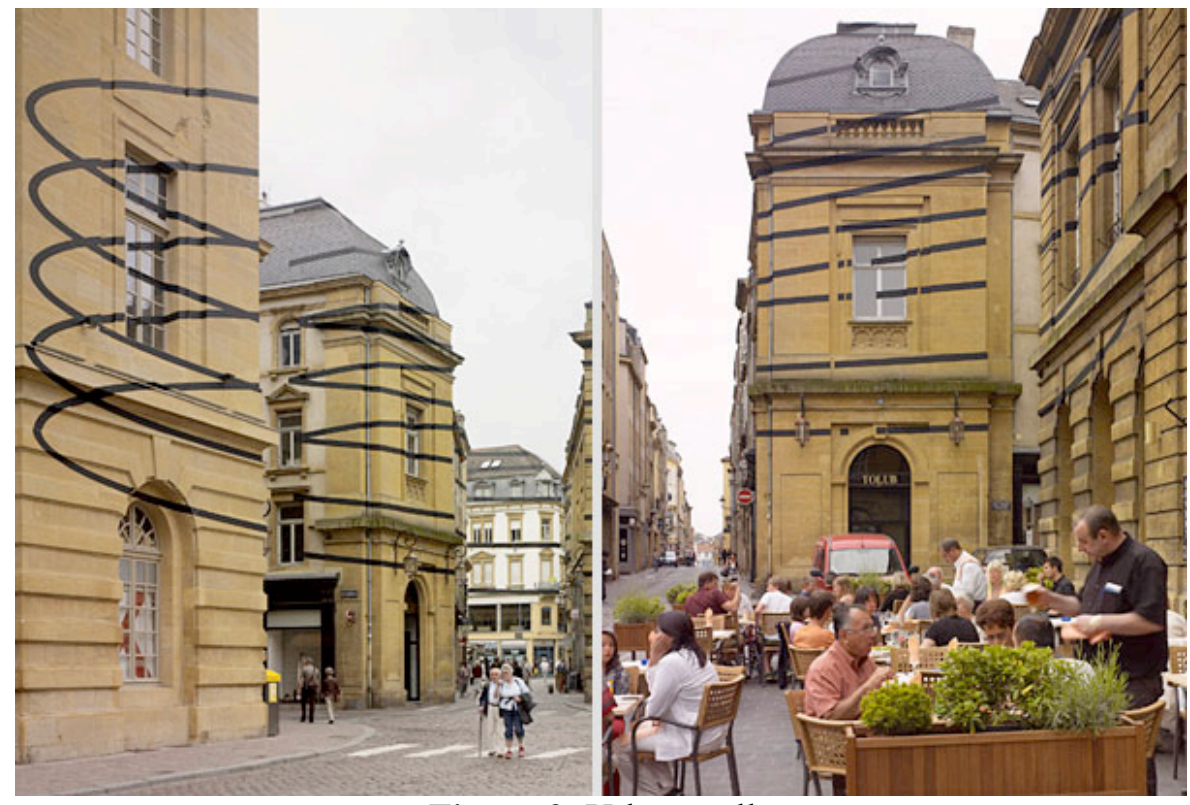

Figure 2: Urban walls

\section{FACTORS AFFECTING THE MODERN FORMATION OF VIEWS AND SIDES}

the package can be more complete than factors in the formation of urban views and sides can be provided. From a substantive point of these factors can be categorized into five main groups of factors that include environmental, employers, design factors, factors superior construction and operational factors. 
- Environmental factors: environmental factors are the most important factors in the formation of façades and walls; it had a larger role in the past, but construction is now under consideration. Such as the climate and topography, local materials, land values, fashion and culture on the construction, the peripheral sides, image and efficiency of urban space are in this category. Considering these factors could respond at least two sets of concerns of urban design; First, Second according to the principles of sustainable development and the principles of environmental perceptions of citizens (Mollaei, 2004).

Here, employer means the person who intends to build by the aim of building a house, workplace or investment on a land. This factor has assumed a strong role in the formation of Views and walls; the effect of environmental factors such as land value, the value of construction materials, fashion and culture, it makes more effect on employers. Quality-aversion, taste-orientation, and rent-collection are the damages that threaten the employment factors.

- Design elements:

Design factors can include designers and construction professionals working Dstandr ideology and thought they knew. These factors are of special importance because it is the responsibility of advising employers in the construction of the theoretical principles of the group;

However, it can damage as well as value-avoidance, passivity-oriented, innovation-oriented authoritarian and on the factors observed.

- Construction factors:

The wide range of factors involved in the construction are included; Producer, quality and manner of construction of buildings, materials available in the market and their price, manpower and so on are; Of the harm that can be cited such factors as quality-aversion, extreme fashions, knowledge-aversion and human resources are ineffective.

- Superior performance factors:

Although the factors mentioned above are very important, but superior performance factors as quality of construction involves the executive and controlling operating at a different level than the top level. These standards and laws enacted and mechanisms are included on the supervision and development. However, these factors are also exposed to several injuries, including no access to clear and trick-taking and fulfillment-aversion, generalization, change-averse, Abuse-rearing, formalism (mortgage or rent engineer specialist Signature ), specialty-flight and margin mentioned processing (Gorji, 2006: 15).

\section{ELEMENTS THAT FORM THE WALLS}

The walls of the building are composed of elements that designers can shape and composition desirable to form the frontage by identifying and correct understanding theses elements. These elements include: entrances, windows, terraces, roof trailing edge (skyline), the main chamber building (areas including the aforementioned elements), volumes come out and you're gone. A proffessional group works on the exterior of buildings and the urban environment, the aspects of color, size, materials proper, full and empty spaces, facade, and principles of harmony (Yousefi, 2009).

Color is the most important visual element from the burden of emotional, so it has special force in spreading the news visually. Color not only has general meaning that is widely accepted, but also has a symbolic meaning as well, in addition, "the people arrive each character has their personal tastes in color choices are (Dandis, 2004: 87). 
Color and texture of materials can contain the material and spiritual aspects. Color and texture can be aesthetic elements of buildings and finally "refer face of a city. Among the factors that can have visual symbols, symbols and abstract color can be investigated three terms are 1) the type of color or chroma 2) saturation 3) the brightness. These factors play an important role in place mental health and behavioral (psychological colors) members of society and cause dynamism, vitality and health, etc. in people.

Apart from theoretical discussions, practice drawing in the design process of the building frontage view that the issue is not isolated. In practice, the plan and facade of the building, which are a category level. Effect of the product, that happens in every field of human production is one of the things that cause the dysfunction of the traditional view in architecture today, the new architecture is fully threedimensional design to be submitted; and this issue has overshadowed posing as an element adhered surface.

Although architects believe that facade is considered as a key element of Architecture, and in this regard some interesting experiences have been done. It seems that the traditional concept facade is changing and the shell, which is broader, it is gradually replacing, In this case, we face new materials that should have certain features and require the implementation of its provisions. New or old materials in the form of materials that are used today should have the following features:

1) Certified standards.

2) use of materials with durability and quality

3) Building a sustainable features (Fallah, 1387).

4) implementation of the approved standards of construction are located.

5) No dangerous materials during events such as earthquakes (such as crushed glass, clay bricks and blocks, etc.) If you use them, special measures should be considered.

6) materials are chosen to suit the climate.

7) having the ability to repair and replace.

8) having easy maintenance.

\section{SOCIAL INTERACTION}

Social interaction means to create relationship between two persons or more that leads to reaction interaction between them that this kind if interation is known for both of them. So, nonesense relationships are not considered in this definition. Of course, there are more definitions foe social interactions, for example, social interaction can be known as a physical issue, a looh or a conversation one of the defining relations are not without meaning. In space and their membership in groups and social networks (Daneshpour, 2007, 22). Exchange of information and ideas among human beings, social life is the most basic needs of communication as the link, the person is connected to the community. Activities such as interacting with others and see the activities of the people, by providing social background and socialization, the development of the human person. Communication and exchange of actions and reactions of the human habitat, which leads to a balance satisfying. Lack of communication means relative stagnation in human life and is an obstacle to any kind of social progress.

\section{APPROACHES TO THE STUDY OF SOCIAL INTERACTION}

1. The macro-sociological approach The underlying idea is that social determinism in the view of social systems and norms of behavior set by Ala. Factors such as social class, race, income or all of the interactive behavior influence our political system affords.

2. Person's perspective (psychological approach)In the view of factors such as education, intelligence, physical appearance, personal attitudes or communication skills play an important role in how people interact with each other. 
3. Check the level of their interaction processes Wider social system and individual character, in fact, the creation of social interaction. The result will be a new interactive about the proper ways to behave In That Situation, Knowledge And Underpins Our Expectations (Frgas, 1947, 26).

\section{FACTORS AFFECTING SOCIAL INTERACTIONS}

Theoretical Lang in the book of Genesis says that if people need to have social contact, wherever it provides in the field. Social interaction between human needs and to answer affiliation and sense of belonging to a place that is a necessity because of the desirability of social interaction. Therefore every opportunity to achieve such an order has been positive.

Another reason is that activities such as interacting with others and see people's activities, by providing social background and socialization contribute to the growth of the human person. Amos Rapoport of the most prominent theorists of behavioral science has shown that attention to urban issues. John Lang has also explores the role of behavioral science in environmental design. Lang in his work entitled "creation of architectural theory" studies the human understanding of space and environemental factors, and he knows the people's imagination of environment as a plan that shape the behaviors and activities of people in different fields (Kashanijoo, 2010: 104).

Human needs based on direct contact with the environment represent a direct experience of space, people and social activities such as interacting with friends, gatherings, walks, games, entertainment, as well as sports, physical activity, ability to compete play a direct role to create optimal mental image in people, dynamism and excitement, new experiences and environmental education, (whyte, 1980). Another view is regulatory requirements as facilities and events about which one of the determining factors in the accountability of space.

\section{ENVIRONMENTAL AND SOCIAL INTERACTIONS}

John Lang among researchers that the main focus of his research is to investigate the role of behavioral science in environmental design. Lang in his work entitled "creation of architectural theory" studies the human understanding of space and environemental factors, and he knows the people's imagination of environment as a plan that shape the behaviors and activities of people in different fields (Kashanijoo, 2010: 104). Lang noted that the normative theories in the comments lot about the impact of design on people's social interactions. Due to the different aspects that have been raised in the context of social interactions, designers have to use different strategies in order to increase opportunities for interaction and communication work in buildings. While the design of privacy and control are concerned spatial domain (Lang, 2004).

\section{VISUAL COMFORT}

Visual comfort can be described for places that these places because of the quantity and quality of information and the absence of an offer to be a healthier, safer and better used by Official regulations or a higher social and mobile are also in this respect. (Salehi, 2007: 6) Important component of man-made visual comfort and secure environment is essential Because for living and life, the town house is large, characteristics and advantages as the home must be habitable and comfortable makes life good. The city also has qualities and features to provide comfort, convenience and security. Also in such a house should be warm and friendly and pleasant environment to provide the possibility of the good life (Lynch, 1993:17)

- Pollution symbol (information and environmental signals)

Pollution is a symbol of any lacuna thtat occur in the two elements of sense and concept. For example, information is vague, incomprehensible or irrelevant to the location and type of pollution is a symbol. There is also a lot of information in one place may be interpreted to mean the loss of that information. (Lynch, 1993: 24 and 23) Including indices indicate the quantity and quality of environmental information includes the following:

- The correct location map 
- Stands and routing

- Clear symptoms and use of words, symbols and schematics International

- Visual pollution (visual disturbances views, volumes and elements)

City is not the only factor that is they are seeing millions of people from all walks, sometimes I remember watching it would be fun. Consider now the city is full of visual pollution, as a result it causes negative effects on the human psyche. Watching the city that Lynch is considered is unpalatable because it makes fun. Of course, it should also be noted that the turbulences environment and a pleasant surprise, but it should be clear enough that the overall environment of the battle. (Lynch, 1993: 11).

- Visual pollution indicators

- There are buildings and facades appear dirty and defaced

- The coordination and integration of building volumes

- Disorders, as well as paintings are dirty and broken boards

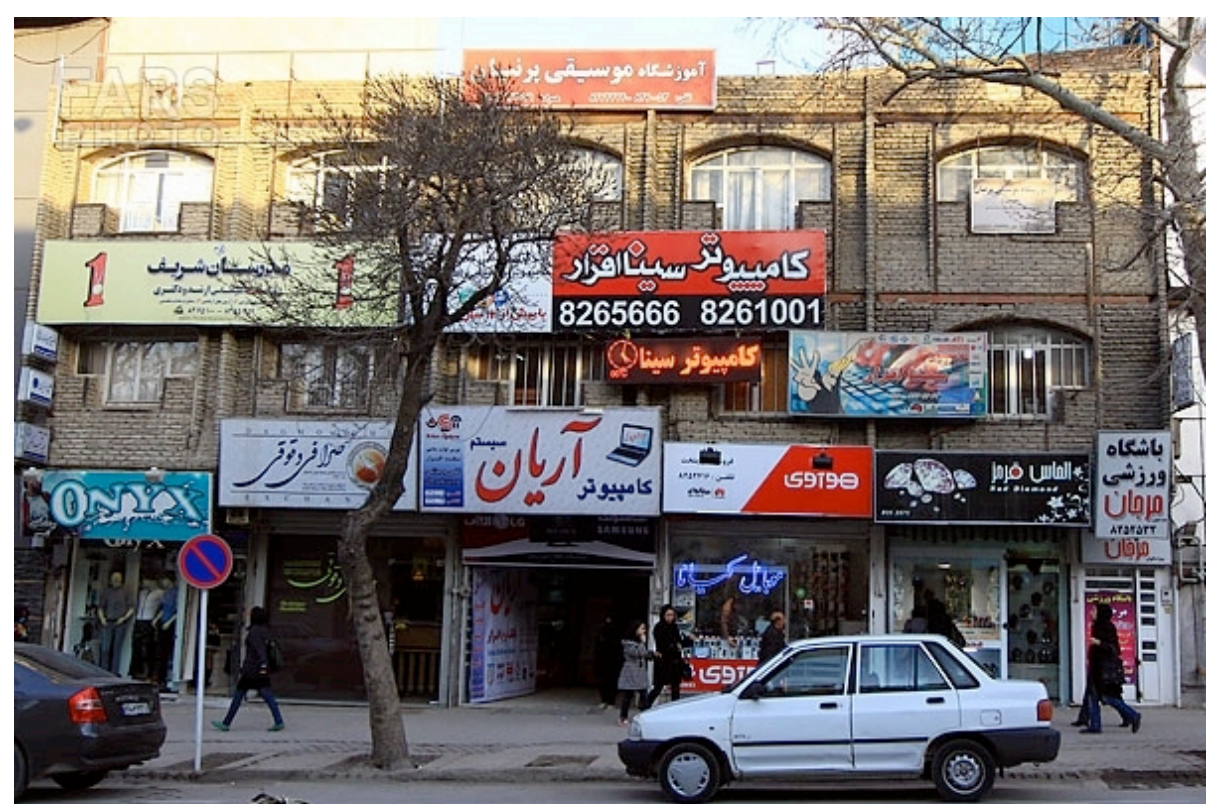

Figure 3: Visual pollution in walls

\section{CONTAMINATION OF COLOR IN THE SURROUNDING ENVIRONMENT}

Human surrounding environment surrounded by the colors in the world around us generally consist of two most important visual element. These two elements are interdependent, each form and color (Bahadori, 2001: 42). For all conditions, which is undesirable color contamination caused by the human perception of color environment can cause him discomfort and may cause undesirable and abnormal behavior in him. In general, a color image of a city can be summarized in the following elements

- Body and Exterior Residential, commercial, administrative and cover the roof mural

- Colors and urban furniture Flooring

-LED lighting, green spaces, fountains and signs of a city at night - Light pollution 
Any form of abuse, uncontrolled and unwanted, unnecessary, or too high a standard and intensity of light, called light pollution. Besides the lack of lighting in public spaces and urban environment also count the pollution. Effective and functional parameters of light with two brightness and lighting approach, including social security, traffic safety, as well as beauty and landscaping night. Hard Lewis Burke says you should avoid city lights and take advantage of gentle light. In his view, better low light in the streets of the old Germany, pleasant and beautiful than the status quo. Japanese Motokasihy tells us in today's world, always penetrating rays and light waves, bombarded. Appropriate to re-light, pale and delicate to achieve. Some light pollution indicators that measures the brightness of the quantity and quality of urban spaces include:

- The amount of light in the main space in the side spaces

- The ability to recognize a person's face (from a distance of 25 meters within the main spaces and 15 yards in the side spaces)

- The ability to view specific signs and boards Enhancing Directions and places at night

- Lighting quality signs and elements

- Entrance lighting quality streets and secondary roads

- There are dark corners of the pedestrian path

- The darkness caused by broken lamps and burnt in space

- The quality of light in the courtyard of trees, shrubs and park (Salehi, 2007: 8).

\section{CONFUSION IN URBAN VIEW}

The urban landscape is all natural and artificial elements (Buildings and their extensions, street furniture, vegetation, etc.) visible from public areas including streets, squares, public nodes and zones. In fact, the identity of the city's urban landscape and dealing and the first thing that citizens can communicate with the city and just endlessly puts him under the influence. Urban landscape reflects disorganization irregularities in the structure and behavior of city planning and landscape reflects the proper relationship between the city and the citizens. Much of the identity of effects that urban residents of the city are gradually and over time. Colors on the unconscious mind influences, advertising messages alter consumer behavior among citizens, building facades with lines and texture violence, gentleness, urban furniture logical relation between the city and its citizens, urban and green spaces between the buildings provide places for citizen interaction. Sidewalks and structure are essentially determines what part of the city and in what form, and therefore define security presence in urban spaces, its buildings reflect the city's architecture with its past and also reflects the cultural and spiritual inhabitants, the height of buildings and skyline in the streets, citizens look to the sky and determine depth.Vertical elements superfluous and useless, a lot of pedestrian bridges, intersections Interchange in large numbers, traffic lights and look ugly and unnecessary all perspective and insight into the depth and distant horizons of the citizens and the mental spaces limits. The urban landscape implies religion and ideology. The presence of old structures and buildings that should not be forgotten original cities represent the past and the sense of belonging for people. So each event shouldn't be accidental except in special cases, and each element in to leave a deep impression that the effect is negative if the form is not repairable Rich.

Urban landscape disturbance can be caused by the following:

- Failure to observe the sky

- Abnormal use of lines and forms in buildings and Views 
- Disorganization gender used in shell and chambered city (building bricks, elements on the facade, flooring, sidewalks and streets, etc.)

- The lack of proportionality in the use of materials

- Late in the views of urban waste (waste elements Next, the author defines the elements that gradually building facades and streets were added by citizens or organizations, such as power substations and telecommunications equipment plus citizens on balconies, kiosks and ....)

- Dysplasia and irregularities in corporate and advertising boards

- Irregularities in the layout of information in the field of urban and inefficient methods (such as installing scaffolding and curtains)

- The release of Views (buildings without facing)

- The presence of vertical elements and without reason

- Excessive use of slogans and repeated text messages

- The presence of unsuitable elements of urban furniture - Inappropriate use of color in urban furniture, urban elements, wall paintings and ... wrong.

- Avoid visible on the horizon Urban Perspective

- The presence of dry and technical structures in the body of the city (roadway bridges, intersections, etc. Interchange.)

- Inadequate lighting at night

- Lack of attention to values and cultural buildings in the city

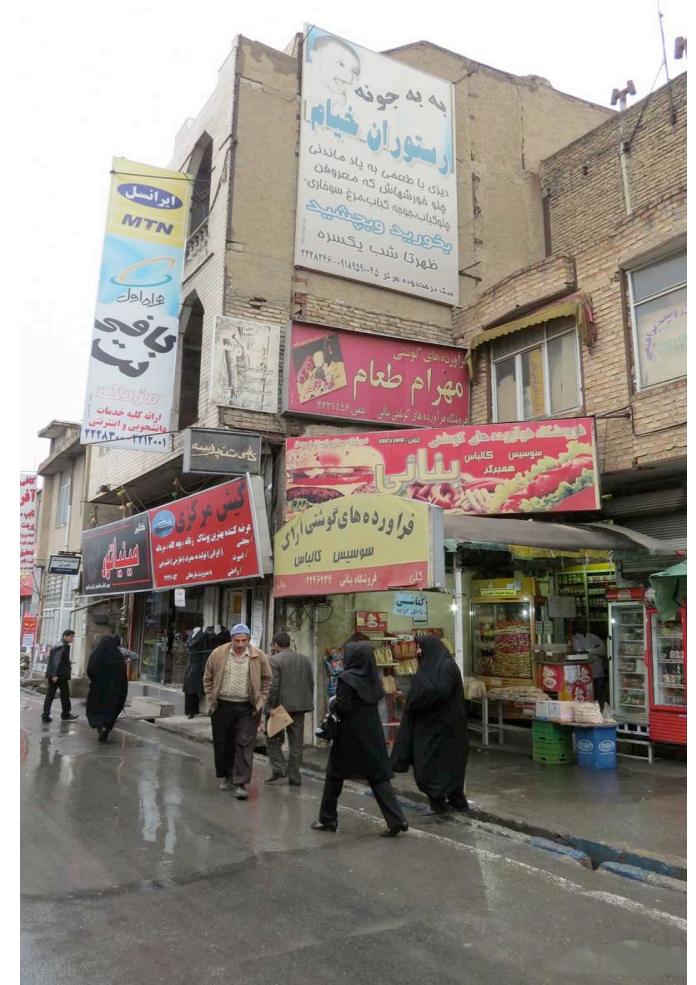

Figure 4: Confusion in urban view 


\section{SOCIAL INTERACTIONS IN THE CITY}

Among human communities, cities can be due to population density, speed and dynamics of activities, specialization and division of labor distinguished. Organic structure of the city is such that the level of social intercourse is very bulky but superficial, transient, unstable and relatively informal and more of the traditional norms of relations between urbanization and formal norms of the law is to determine the weight of social relations. Such an atmosphere makes the relationships between people living in the city (compared to small rural communities) is not of sufficient depth and quality. As a result of the emotional vacuum and lack of identity and social belonging savings will be less supply. In such circumstances, urban people are scrambling to meet the need for social belonging and identity, develop social relations will follow, but what he's trying to be largely neutral texture, structure, fabric, wall spaces in the city that limits the level of urbanization communication and social interaction. Naturally, the greatest help to promote a sense of social belonging is identity and emotional needs of the citizens. Since the human look to the city and citizens requires mental and social well-being and needs of citizens is concerned,It is essential that the planning and management of urban walls and bodies cultural and social development of the relations and human relations in the city.

Some of the structural barriers that impede the development of the city walls and body spaces deep relationships and social interactions are as follows:

1. Wrong body tissue and architectural monuments, squares, streets and markets 2. incorrect design and incorrect posture different parts of residential, commercial, administrative and cultural

3. In view of the apparent confusion and visual disturbances wall in such a way that it leaves a negative impact on the psyche of the citizens including the ways in which this situation can be corrected, link between aesthetic aspects, cultural and artistic aspects of collective life

\section{CONCLUSION}

To achieve visual comfort in the walls of the city to improve the quality of social interactions of many components are involved. Cleaning the air, visual appearance and color in the face of the walls of buildings and municipal buildings, the quality of urban spaces and access to network traffic, according to municipal utilities, environmental quality have a significant role in the promotion of visual comfort. However, the urban walls are not in suitable condition in terms of environment and other important factors that this causes decreasing visual comfort and environmental qualities in it. The urban walls are worn and inappropriate in terms of quality of light in an improper state, building mostly black, dark materials, construction quality. Achieving visual comfort requires a coherent program and cooperation by the authorities and the public. Such measures can reduce the visual pollution, and urban environment and provide visual comfort in mental peace and social interactions for citizens.

\section{REFERENCES}

Pakzad, J. Theory and urban design process, Shahidi Publications, Tehran, 2003.

Yousefi, N. The concept of "light" from the viewpoint of Imam Mohammad Ghazali and Louis Kahn, National Conference and Congress Chhrmyn higher education institution grave, Mashhad, 2010.

Yousefi, N. The concept of "light" from the viewpoint of Imam Mohammad Ghazali and Louis Kahn, National Conference and Congress Chhrmyn higher education institution grave, Mashhad, 2010.

Yousefi, N. PourKarimi, A., Facade role in shaping the physical environment in national building regulations, national building regulations of the National Conference, Shiraz, 2009.

Banimahd, A. Urban view, Deputy Director General of the Department of Housing and Urban

Development to develop and promote national building regulations, 2007.

Mollaei, and contributing factors in the formation of modern façades and walls, Alborz Province of

Construction Engineering, 2004.

Dandis, D, principles of visual literacy, translation Masoud Sepehr, Tehran, Soroush (Press

Broadcasting), Tenth Edition, 2004.

Daneshpour, A., Charkhchian, CE, public spaces and factors affecting communal life, Journal of Bagh-e Nazar, Issue 7, 2007. 
Frgas, J. Psychology, social interaction, interpersonal behavior, translated by Mehrdad Firouzbakht and Khashayar Beigi, Mahd Publications, Tehran, 2000.

Kashanijoo, good to explore theoretical approaches to urban public spaces in Identity journal, Issue 6, the fourth year, 2010.

Lang, C, creation of architectural theory (the role of behavioral sciences in the design environment), translated by Alireza Einifar, Tehran University, Tehran, 2004.

Salehi, A. Visual comfort, publishing, Tehran, 2007.

Lynch, K. Urban view, the translated by Manouchehr Mozayani, Publications of Tehran University, Tehran, 1993.

Bahadori, M, psychology, functional colors, Madreseh No publications, Tehran, 2001.

Whyte, w, social laife of small urban space, conservation foundation, 1980. 